\title{
THERMAL RESPONSE OF AN AERATED CONCRETE WALL WITH MICRO-ENCAPSULATED PHASE CHANGE MATERIAL
}

\author{
Dušana HALÚZOVÁ ${ }^{*}$
}

\begin{abstract}
For many years Phase Change Materials (PCM) have attracted attention due to their ability to store large amounts of thermal energy. This property makes them a candidate for the use of passive heat storage. In many applications, they are used to avoid the overheating of the temperature of an indoor environment. This paper describes the behavior of phase change materials that are inbuilt in aerated concrete blocks. Two building samples of an aerated concrete wall were measured in laboratory equipment called "twin-boxes". The first box consists of a traditional aerated concrete wall; the second one has additional PCM micro-encapsulated in the wall. The heat flux through the wall was measured and compared to simulation results modeled in the ESP-r program. This experimental measurement provides a foundation for a model that can be used to analyze further building constructions.
\end{abstract}

\section{INTRODUCTION}

The most significant studies of phase change materials (PCM) began in the 1980s (Telkes and Raymond, 1949), with a focus mostly on building applications. In recent decades, these materials have become an attractive option for energy conservation in building walls. Interest is rapidly accelerating due to increasing user demand for thermal comfort and efforts to decrease the cost of HVAC (Bogdan, 2011; Castell et al., 2010). Phase change materials belong to a group of latent heat storage materials. When a material changes from a solid to a liquid phase and viceversa, a thermal energy transfer occurs. This is called a "change in phase". There are numerous candidates for latent heat storage covering a wide range of temperatures (Lorsch et al., 1976; Lane et al., 1975; Abhat, 1983). The ideal candidate has several important properties: a high fusion heat, high thermal conductivity, high specific heat and density, long-term reliability during repeated cycling, and low volume changes during phase transitions; it should be noncorrosive, non-toxic and non-flammable and should exhibit little or no sub-cooling (also "called super-cooling"). With

\section{Address}

1 Department of Building Structures, Faculty of Civil Engineering, Slovak University of Technology, Bratislava, Slovak Republic

Corresponding author: dusana.haluzova@gmail.com

\section{Key words}

- Latent heat,

- phase change materials,

- energy simulation. 

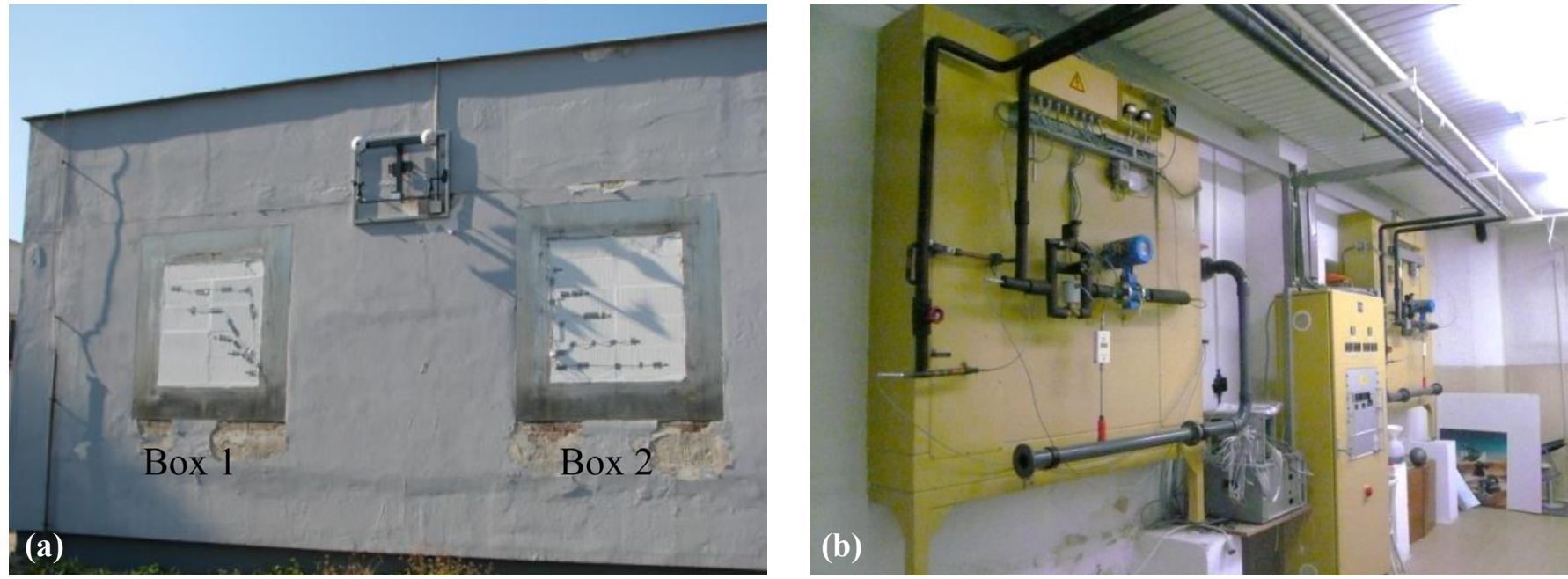

Fig. 1 The finished samples ready for measurements (a), with the laboratory equipment (twin-boxes) viewed from the inside. In the middle, there is the regulation of the whole system (b).

melting points from 10 to $90{ }^{\circ} \mathrm{C}$ to be used for encapsulation. Microencapsulation is widely used in building applications to increase heat transfer areas, to reduce the reactivity of PCMs towards the outside environment, and to prevent unwanted volume changes. In most cases a microcapsule is made of thin, high molecular weight polymeric film. The size of a microencapsulated PCM has a range from $1 \mu \mathrm{m}$ up to $1000 \mu \mathrm{m}$. The second method is macroencapsulation, which represents a PCM in the form of bigger capsules such as tubes, pouches, spheres, panels, and other containers. These can be directly used as a heat exchanger or incorporated into the building construction. The disadvantage of macroencapsulation is the poor conductivity of the PCM. When using encapsulation, special attention must be paid to the function of the construction material; the encapsulated material must not adversely affect the mechanical strength of the construction material.

This paper presents an experimental investigation of Micronal DS 5001 microencapsulated material incorporated by BASF Inc. into an aerated concrete block produced by HplusH. These blocks were studied in the Central Laboratories of the Slovak University of Technology in Bratislava. In the laboratory equipment (so-called "twin-boxes"), two sample walls were investigated in actual climatic conditions. The results acquired characterize the behavior of heat flux during 6 days of measurement. Finally, a simulation model was created for further analyses of other building constructions.

\section{EXPERIMENTAL SET-UP}

For this experiment, the Central Laboratories of the Slovak University of Technology in Bratislava were used. The first simulations indicated an optimal period for the measurements. Autumn was chosen as it is a period when temperatures oscillate around the melting point of the PCM.

Over two days two identically-shaped samples were built in socalled "twin-box" laboratory equipment. Aerated concrete walls were built in an area designated for the samples. The dimensions of the new walls were $1200 \mathrm{~mm} \times 1000 \mathrm{~mm} \times 100 \mathrm{~mm}$. The area for the sample was $1200 \mathrm{~mm} \times 1200 \mathrm{~mm}$, but for easier removal, it was nec-

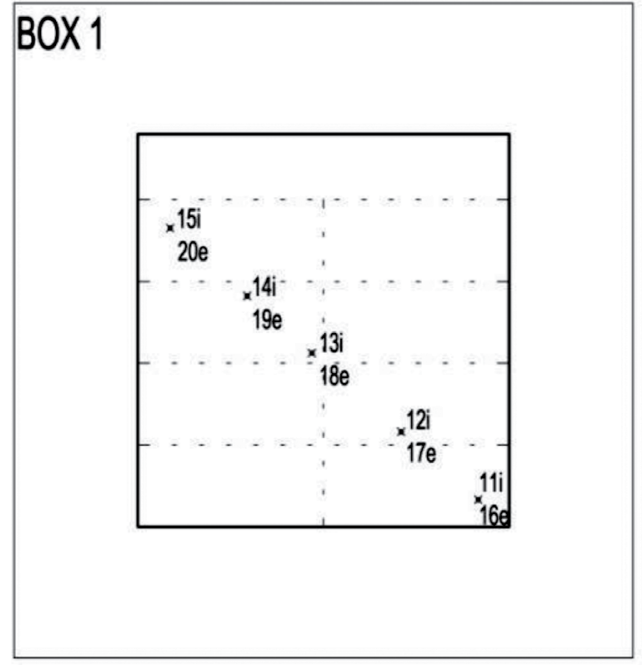

(a)

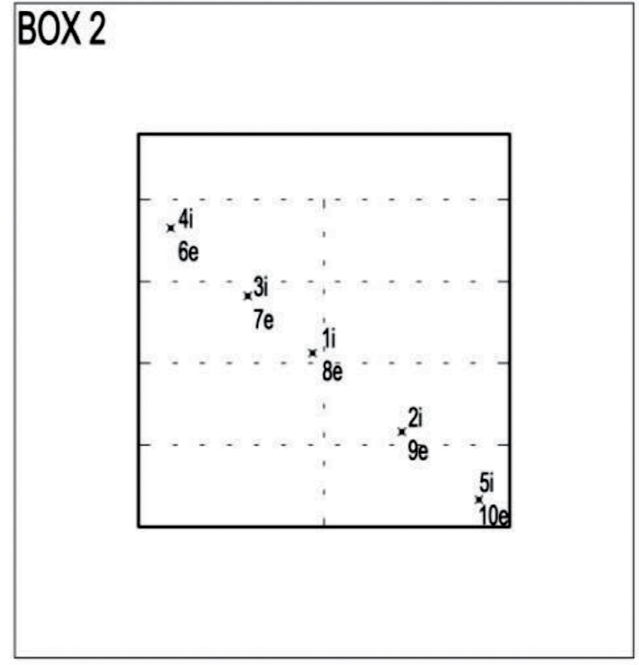

Fig. 2 The layout of the thermocouples: the view from the outside (a), Section of the twin-box: 1 - measured sample, 2 -expanded polystyrene, 3 -steel mesh, 4-fan, 5 -dividing curtain, 6-temperature sensor, 7 -humidity sensor, 8 -heat exchanger, 9 -fine nylon mesh, 10 - interior wall of the twin-box (b). 
essary to leave a gap above the sample. Both sides of the sample were doubly painted with a white exterior waterproof coating. While constructing the samples, thermocouples were attached on the inside in a diagonal direction. Thermocouples were placed on the outside in the same position.

Box 1 represents a traditional aerated concrete wall made of Celbloc Plus produced by HplusH. The second one, Box 2, contains the same aerated concrete wall but with the encapsulated PCM Micronal DS 5001. The manufacturer listed a thermal conductivity of $0.1 \mathrm{~W} /$ (m.K) for the aerated concrete block both with and without the addition of the PCM. The reason is the quantity of PCM in the block, which is only 5\%; more of the PCM would influence the mechanical properties of the block. Micronal DS 5001 has a latent heat capacity of $110 \mathrm{~kJ} / \mathrm{kg}$, a thermal conductivity of $0.2 \mathrm{~W} /(\mathrm{m} . \mathrm{K})$, a melting range of $24-26^{\circ} \mathrm{C}$, and an apparent density of $250-350 \mathrm{~kg} / \mathrm{m}^{3}$.

All of the measurements were conducted in actual climatic conditions that were recorded by other equipment. These data were used for energy simulations in ESP-r. Over 6 days the external temperature, relative air humidity, direct, global and diffuse solar radiation, wind speed and direction were documented.

\section{RESULTS}

In this experiment the heat flux entering through the aerated concrete wall with the PCM was compared to the reference wall without the PCM. Besides this quantity, the wall temperatures, temperatures in the twin-boxes, and temperatures of the compensation room were registered as well.

The heat flux showed a fluctuating character. This was caused by the oscillation of the equipment's amplitude. The first twin-box, where the traditional aerated concrete wall was placed, had an amplitude of 5W. The second twin-box, with an aerated concrete block with the PCM, had an amplitude of $10 \mathrm{~W}$. For a better visual display, an exponential trend-line was used.

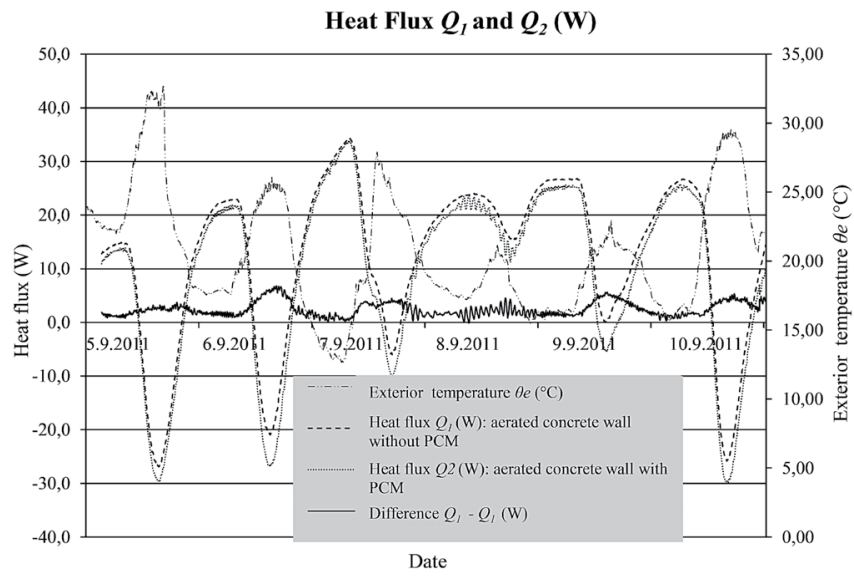

Fig. 3 Heat flux of a traditional aerated concrete wall and a wall with the PCM during the measurements from 5.9. - 10.9.2011.

Figure 3 shows the behavior of the heat flux during the measurements. Major differences occurred concerning the maximum day temperatures and high values of the direct solar radiation. In this case the difference in the heat flux is $5.4 \mathrm{~W}$ on average. The maximum difference was achieved on the second day of the measurements. On this day, the power consumption for the cooling increased by $8.7 \mathrm{~W}$ in the twin-box with the PCM wall in comparison with the twin-box with a traditional aerated concrete wall. During the nights, when the outside temperatures ranged from $12{ }^{\circ} \mathrm{C}$ to $18^{\circ} \mathrm{C}$, it was necessary to heat the internal space of the twin-boxes. In the twin-box with an aerated concrete wall without the PCM, it was necessary to increase the heat input compared to the twin-box with a PCM wall. The difference was $3.8 \mathrm{~W}$, as the maximum difference achieved upon the measurement. Whereas PCMs decreased the heat flux at lower temperatures, on warm days they had a negative effect and increased the heat flux in the aerated concrete wall. This happened due to the slower response of the whole system where the PCM is used.

\section{SIMULATION MODEL OF THE TWIN-BOX}

For the building simulation, the ESP-r integrated energy modeling tool was chosen. In this program, a two-zone model was created. The first zone represents the area where the examined sample was built. The second zone is separated by a steel screen. The movement of air is supplied through the grids. The first grid is located in the upper part of the twin-box; the second one is presented in a vertical position in the lower part of the twin-box.
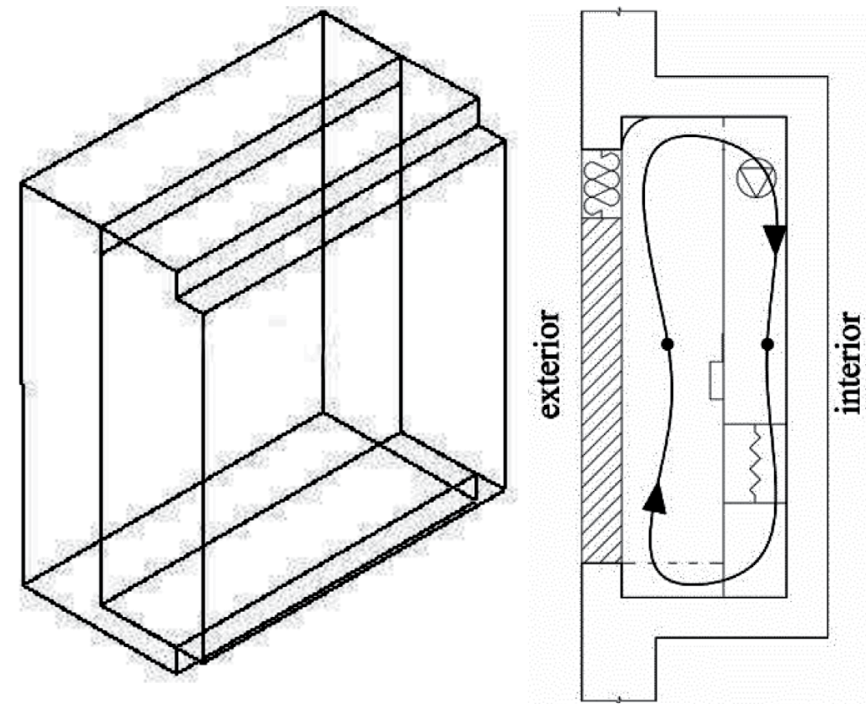

Fig. 4 Two-zone simulation model - the investigated sample is in the front raised part (a), the air flow is in the twin-box (b).

In the simulation, simplifications had to be introduced. There are some unmeasured parameters such as the grid resistance, impact of the heat bridge, air change rate, etc. Another missing parameter was the convective heat transfer coefficient (forced convection on the internal surface, free convection on the outside surface). The movement of air on the internal surface of the sample was much faster than on the outside surface. This was caused by the constant air movement in the twin-box supplied with a fan. This fan was connected to the system regulation, which was set at $23.5^{\circ} \mathrm{C}$. Hence at a higher day temperature and lower night temperature, the air velocity in the twinbox was much higher. This caused a higher convective heat transfer coefficient on the internal surface of the sample. When the outside temperature oscillated around the temperature defined by the regulation system, the convective heat transfer coefficient was much lower on the internal surface of the wall. In the simulation, a convective heat transfer coefficient of $90 \mathrm{~W} /\left(\mathrm{m}^{2} . \mathrm{K}\right)$ on the internal surface was used. On the outside surface it was $23 \mathrm{~W} /\left(\mathrm{m}^{2} . \mathrm{K}\right)$. 


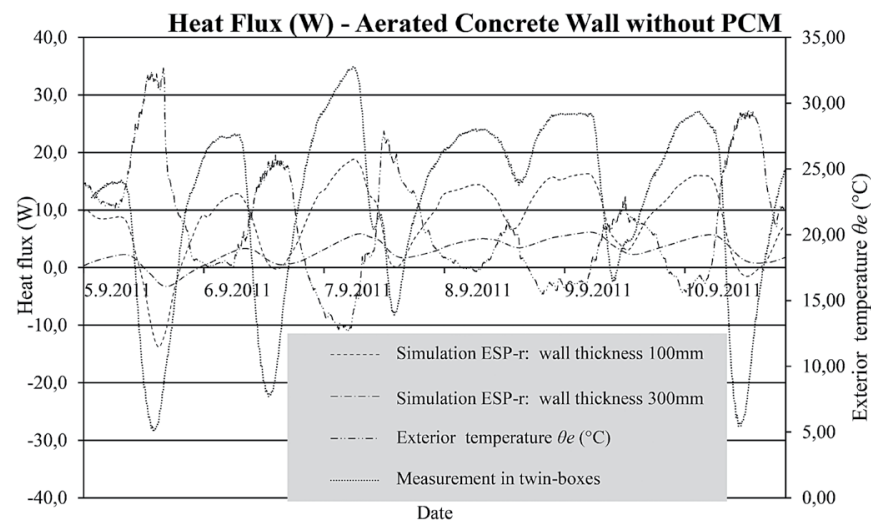

Fig. 5 Heat flux of the traditional aerated concrete wall: simulation and measurement.

Figures 5 and 6 show the heat flux of both walls examined in the twin-boxes. The comparison was carried out between the measurement in actual climatic conditions and the simulation with the ESP-r tool. The shape of the curves is very similar, except for the greater apparent differences, especially in the extreme values. These deviations are caused by the missing parameters mentioned above. The major discrepancies between the measurements and the simulation were caused by an inaccurate estimation of the convective heat transfer coefficient.

\section{CONCLUSION}

Utilizing experimental measurements, the impact of an aerated concrete wall's configuration was studied. Heat flux was chosen as the key comparative criterion. The results show the low impact of an

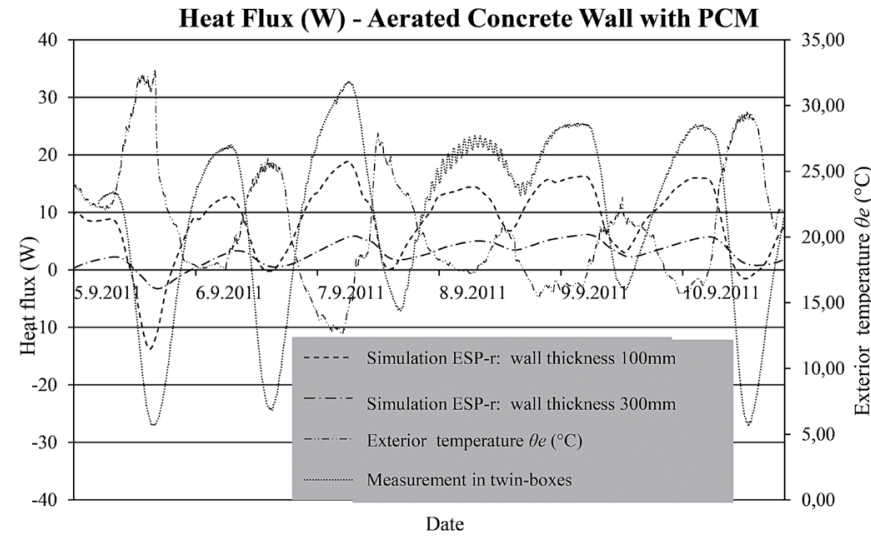

Fig. 6 Heat flux of the aerated concrete wall with PCM: simulation and measurement.

aerated concrete wall with the PCM on heat flux compared to the traditional aerated concrete wall due to the volume of the latent material contained in the block. As it amounts to only $5 \%$, it is not sufficient to significantly influence the heat flux. In fact, on warm days, a wall with the PCM acts like a solar wall and increases the heat gains in the interior. Incorporating the PCM into building constructions has an effect up to a certain point. However, the selection of PCMs and their thermal properties needs to be done very carefully. Parameters such as heat capacity, thermal conductivity, content of the PCM, production costs, and many other factors need to be taken into consideration.

\section{Acknowledgement}

This research is supported by the VEGA No. 1/0647/09 research project.

\section{REFERENCES}

Abhat, A. (1983) Low temperature latent heat thermal energy storage: heat storage materials. In: Solar Energy, pp. 313-332.

Bogdan, M. D. (2011) Thermal energy savings in buildings with PCM-enhanced envelope: influence of occupancy pattern and ventilation. In: Energy and Buildings 1, pp. 101-107.

Castell, A. - Martorell, I.- Medrano, M. et al. (2010) Experimental study of using PCM in brick constructive solutions for passive cooling. In: Energy and Buildings 4, pp. 534-540.

Dincer, I. - Rosen, M. A. (2002) Thermal energy storage: Systems and Applications. John Wiley \& Sons, Chichester.

Hawes, D. W. - Feldman, D. (1992) Absorption of phase change materials in concrete. In: Solar Energy Mater Solar Cells, pp. 91-101.

Lane, G. A. - Glew, D. N. - Clark, E. C. et al. (1975) Heat of fusion system for solar energy storage subsystems for the heating and cooling of buildings. Charlottesville, Virginia, USA.
Lane, G. A. (1976) Encapsulation of heat of fusion storage materials. In: Proceedings of 2nd Southeastern Conference on Application of Solar Energy, pp. 442-450.

Lane, G. A. (1980) Low temperature heat storage with phase change materials. In: Int J Ambient Energy, pp. 155-168.

Lane, G. A. (1983) Solar heat storage. In: Latent heat material 1, vol. I, Background and Scientific Principles, CRC Press.

Lane, G. A. (1986) Solar Heat Storage. In: Latent Heat Material. vol. II, Technology, CRC Press.

Lorsch, H. G. - Kauffman, K. W. - Denton, J. C. (1976) Thermal energy storage for heating and air conditioning, Future energy production system. In: Heat Mass Transfer Processes, pp. 69-85.

Telkes, M. - Raymond, E. (1949) Storing solar heat in chemicals a report on the Dover House. In: Heating and Ventilating. 